\title{
A VIAGEM SEM FIM PELAS TERRAS DOS MENINOS PELADOS: UMA LEITURA PSICANALITICA
}

\author{
NEUZA CECILIATO DE CARVALHO ${ }^{1}$
} CARVALHO, N.C. de. A viagem sem fim pelas terras dos meninos pelados: uma leitura psicanalitica. Semina: Ci.
Soc./Hum., Londrina, v. 13, n. 3, p. 180-185, set. 1992.

RESUMO: A análise d' A terra dos moninos pelados, de Graciliano Ramos, procurou mostrar através das teorias psicanarticas de S. Freud e J. Lacan que a estrutura narrativa revela a trajetória do dellio da personagem em busca da realizaçáo do desejo.

PALAVRAS-CHAVE: Literatura; Psicanálise; Estrutura narrativa; Mundo real/mundo imaginário; Significação simbólica; Delirio.

\section{INTRODUÇĀo}

A plurissignificação e a polissemia, enquanto elementos intrínsecos de uma obra literária, permitem ao leitor leituras distintas, que se consolidam nas análises a partir de correntes teóricas e críticas das ciências humanas, ou mais especificamente, das teorias literárias, lingulsticas, sociológicas e psicanalfticas.

A busca de significação de um texto literário parece ser a razão primeira dos estudos empreendidos, principalmente pela psicologia e psicanálise, que farejando 0 rastro do emissor-narrador, procura aproximar a leitura e análise do leitor ao significado mais escondido do enunciado narrativo, bem como procura desnudar a simbologia presente na enunciaçāo.

Em nivel de enunciado, o analista ou o critico literário constrói o significado latente do texto, desmontando a estrutura e identificando a forma estética, com vistas a reconstruir a constituiçāo material, concreta e substantiva do texto literário.

Essa modalidade de análise, sozinha, acaba, porém, por nāo dar conta da significaçāo simbólica e humana que todo grande texto contém, necessitando, portanto, de uma descida a um nivel mais interno do texto que se constitui na enunciaçăo, lugar por excelência da significação, onde o sujeito emissor se "des-conta, escapando-se pela palavra plena, deixando à mostra o modo de contar o que se conta". (CHALHUB, 1988, p. 172-5).

Reconstituir a constituiçăo material e concreta do texto literário e buscar o seu significado escondido é o propósito deste trabalho, que pretende acompanhar o desenrolar da história A terra dos meninos pelados, de Graciliano Ramos, (RAMOS, 1984) procurando associar a estrutura narrativa à busca de realizaçäo do desejo da personagem Raimundo, configurada pelo seu delfrio.

Necessário dizer que a riqueza estrutural dessa obra a sua natureza simbólica permitem ao leitor inúmeras incursôes analiticas, e que a centralizaçăo da análise pela incorporaçäo de alguns conceitos das teorias psicanalfticas de Freud e Lacan nāo tem a intenção de apresentar uma leitura conclusiva e globalizante da obra em questão, nem a certeza de que este novo texto, criado a partir do texto primeiro de Graciliano Ramos, seja inquestionável.

\section{1 - A ESTRUTURA NARRATIVA E A CADEIA SIGNIFICANTE}

A terra dos meninos pelados inicia-se com a revelaçāo do conflito da personagem principal, Raimundo, menino diferente dos demais, que tem a cabeça pelada, um olho preto e outro azul, e que por isso $e_{\text {injuriado }}$ pelas crianças da rua onde mora.

A resoluçāo do conflito aparece jâ no segundo capltulo, quando Raimundo criando nas areias da calçada de sua casa o mundo imaginário do pals de Tatipirun, transporta-se para essas terras maravilhosas, onde todas as crianças são apresentadas à sua semelhança: sem cabelos e com um olho de cada cor.

A centralizaçäo na diferença de Raimundo com as demais crianças do mundo real * representa assim o seu desejo, que se configura no texto pelo delfrio da personagem e pela busca incansável de sua completude enquanto ser.

1 - Prof" de Teoria Literária do Curso de Letras da Universidade Estadual de Londrina, Londrina, Pr., Brasil, Caixa Postal 6001, CEP $86051-970$

- Entenda-se por mundo imaginário a situaçāo vivida na realidade cotidiana da personagem Raimundo. Inversamente a esse conceito, Real, para Lacan, 6 a "realidade do inconsciente". 
E é essa situaçāo criada, a passagem do mundo real - conflitante e desolador para Raimundo, pois torna-se um solitário por ser diferente - para o mundo imaginário. - as terras maravilhosas de Tatipirun, onde todas as crianças são semelhantes a ele - que vai possibilitar a continuidade da história.

A passagem do mundo real para o mundo imaginário se dá quando Raimundo, ao ser molestado pelas crianças de sua rua enconlhe-se e fecha o olho direito, em seguida fecha o esquerdo, não enxergando mais a rua. "E a rua ficava toda escura". (RAMOS, 1984, p. 17).

Ao não ver mais o mundo real, Raimundo deixa de viver a realidade presente, passando a viver situaçōes onlricas no mundo imaginário. Essa transferência de lugar representa assim o dellirio da personagem que busca cobrir a sua falta através da transformação do mundo exterior, criando um outro mundo onde os seres são concretizados pela semelhança com ele próprio: "bem uns quinhentos (meninos pelados), alvos e escuros, grandes e pequenos, muito diferente uns dos outros. Mas todos eram absolutamente calvos, tinham um olho preto e outro azul". (RAMOS, 1984, p. 17)

Na concepçāo psicanalitica, "o registro imaginário está marcado pela presença da relação da imagem do semelhante. É em funçäo desta relação com a imagem do outro que o registro do imaginário é correlato expressivo do desejo". (CABAS, [198.], p. 28).

No registro do imaginário de Raimundo, a sua diferença passa a ser a semelhança e todos se tornam iguais. Ocorre, porém, que essa inversāo por si sơ não ế suficiente para cobrir a falta de Raimundo, pois segundo Lacan, $e$ na forma de construçăo de demandas, de busca incessante, que o desejo é articulado, metonimicamente.

Dessa forma, "o desejo se dá ao nível da representaçâo, tendo como correlato os fantasmas (fantasias), o que faz com que, contrariamente à pulsăo - que tem que ser satisfeita - o desejo tenha que ser realizado". (GARCIA ROZA, [19...], p. 83).

Nesse sentido a estrutura narrativa vai se constituir no encadeamento permanente de situaçōes-desejo de Raimundo com vistas à realização; mas como o desejo é sempre articulaçăo, movimento, processo, passagem, năo tendo um conteúdo, a realização nunca se efetiva completamente,

Isso porque, na visăo freudiana, "o que caracteriza o desejo [-] esse impulso para reproduzir alucinatoriamente uma satisfaçăo original, isto $\hat{e}$, um retorno a algo que jấ nāo ế mais, a um objeto perdido cuja presença é marcada pela falta. [..] 0 desejo é a nostalgia do objeto perdido". (GARCIA ROZA, [19.--], p. 145).

$\mathrm{Na}$ história em análise, o objeto perdido vem a ser a falta, a incompletude de Raimundo, que se materializa na sua diferença em relaça as outras crianças.

Complementando essa concepgão Lacan enuncia que o que determina o sujeito e o significante mestre $S^{1}$. que por sua vez se desdobra em uma cadeia infindśvol de outros significantes, sempre na busca de realizaçăo do desejo, que nunca será satisfeito.
Nesse sentido, a falta de cabelos a a cor diferente dos olhos passa a desdobrar-se em outros significantes para a personagem, constituindo-se o restante da história em uma cadeia de significantes onde o seu problema se repete a cada nova experiéncia vivida por ele no mundo imaginário, possibilitando assim que seu desejo seja realizado, mas nāo satisfeito, sobrando sempre um resto.

E a história prossegue então em razāo do desejo inconsciente de Raimundo de permanecer na sua busca, o que vai permitir a continuidade da aventura pelo mundo imaginário.

O delfrio constrói assim a história, que se apresenta como descondensadora do conflito primeiro, permitindo a Raimundo a sua busca, o que vai proporcionar a convivéncia com o conflito, através dos diálogos entre ele e as crianças do mundo imaginário; das discussōes sobre as diferentes visōes; das aceitaçōes e recusas do protagonista de permanecer naquele mundo de fantasia.

A projeção de Raimundo nas outras personagens se dă, então, pela oposição ou pela identificaçāo, funcionando as crianças do mundo imaginário como o seu duplo, o outro: isso the possibilita o diálogo com o seu contrário, e, conseqüentemente, consigo mesmo, uma vez que essas personagens são projeção dele próprio.

\subsection{A Fala e a Descondensação do Conflito}

Ao se encontrar pela primeira vez com os meninos pelados, Raimundo é indagado por eles sobre o paradeiro de Caralámpia, menina-princesa, amada por todos, que se encontrava desaparecida. Raimundo, que não a conhece, pergunta se é uma laranjeira que havia visto há pouco, ao que as crianças riem e o chamam de bobo.

Sua atitude é a mesma do mundo real, quando os meninos de sua rua o insultam: isola-se, e solitário nảo tem com quem conversar. Ocorre, porém, que nessa nova situaçāo criada no mundo imaginário, Raimundo encontra um interlocutor, o Tronco, que questiona o motivo de seu isolamento e the diz que ele estâ "se afogando em pouca água, que as crianças estavam brincando e que elas são boa gente" (RAMOS, 1984, p. 21). Essa contraposição de opiniăo, a diferença que vem do Outro, permite-lhe a mudança de atitude: Raimundo concorda com - Tronco, esquece-se do acontecido e volta a procurar os meninos pelados.

A história parece mostrar dessa forma que, pelo fato de Raimundo năo ter com quem entender-se no mundo real, ele entra em delfrio, criando assim no mundo imaginário situaçóes onde possa dialogar, mesmo que seus interlocutores sejam objetos ficticios como o Tronco que fala.

Falar de si e de suas necessidades permite o reconhecimento do objeto causa do desejo, como propōe Lacan. É, portanto, no mundo imaginário criado por Raimundo que se encontra o espaço da permissảo da fala, e é justamente nesse espaço que Raimundo consegue simbolizar o seu desejo, introduzindo-o na cadeia signifi- 
cante, o que vai lhe possibilitar a convivência com o seu contrário.

A necessidade da fala, enquanto possibilidade de descondensação do núcleo, faz com que Raimundo passe para a cadeia significante o seu desejo, que se articula metonimicamente através de situaçōes narrativas novas que vão sendo criadas na história. $E$ assim a história prossegue com novas aventuras e com novos personagens.

\subsubsection{O diálogo dos contrários}

A projeçẵo de Raimundo de seu duplo está personificada na história, principalmente pelas personagens Sardento e Caralâmpia, tendo cada uma delas uma relaçāo de contiguidade e similaridade no que respeita à constituição da personalidade do protagonista.

Sardento parece representar um ponto fundamental do conflito de Raimundo, pois apresenta problema semelhante ao dele. Enquanto Raimundo tem um olho de cada cor e a cabeça pelada, Sardento tem manchas no rosto, o que os torna diferentes das demais crianças. $E$ assim o desejo de ambos e o de transformar as demais pessoas às suas semelhanças. Seus problemas săo flsicos, portanto, concretos, e isso năo permite subterfúgios, mas apenas abstração lógica da falta.

Sardento se aproxima de Raimundo logo no infcio da história, e o acompanha pela sua viagem ao mundo imaginário com a intençăo de the confessar o seu desejo. que é pintar o rosto das outras crianças para que elas fiquem iguais a ele. Por muitas vezes Sardento tenta expor o seu plano a Raimundo, ensaia de lhe falar de seu desejo, mas este retarda sempre a sua fala, interferindo com perguntas sobre o mundo de Tatipirun:

" Eu tenho um projeto. [disse Sardento]

" Estou receando que anoiteça, exclamou Raimundo. Se a noite pegar a gente no campo.. Era melhor entrar em casa e deixar a Caralampia para amanhä. (RAMOS, 1984, p. 28)

- O meu projelo é curioso, insistiu o sardento, mas parece que este povo náo me compreende.

"- É sempre assim, disse Raimundo. Faltará muito para o sol se por?" (p. 31)

- Vou contar o meu projeto. disse Sardento

- É bom. Conte. Mas andando assim à toa, sem destino, como é que vocês entram em ca$\operatorname{sa?}^{\prime \prime}(\rho, 36)$

- Quer ouvir o meu projeto? segredou o menino sardento.

" Ahl sim. la-me esquecendo. Acabe deprossa.

"- Eu vou principiar. Otho a minha cara.." (p. 38)

Ao tomar conhecimento da intenção de Sardento,
Raimundo tenta the convencer que o seu projeto 8 impossivel de se realizar, ressaltando que em Tatipirun todos gostam dele, o aceitam como é e nảo o discriminam; diferentemente do que fazem os meninos da rua onde mora Raimundo, em Cambaracá, que o discriminam pelo fato de ter a cabeça pelada e um olho de cada cor.

Ao retardar a fala de Sardento, Raimundo está retardando, na realidade, a sua própria fala, nāo permitindo que o seu problema venha a tona porque isso significa defrontar-se com o seu conflito. Os cortes feitos por Raimundo na fala de Sardento, desviando sempre o seu interesse para as mais variadas coisas, mudando sempre de assunto, retratar bem esse postergar do embate.

Se aceitarmos que a história se constrói pelo delfrio da personagem principal, que o delírio é regido pelo inconsciente, e que Sardento representa o outro lado de Raimundo, o seu duplo, podemos entăo dizer que esta fala retardada de Sardento só vai ocorrer no momento em que Raimundo se sentir em condiçōes de, vendo-se no outro, ver-se a si próprio, porém ver-se ainda como um diferente. Raimundo soluciona o problema de Sardento, mostrando que ele é amado pelas crianças, mas näo resolve o seu conflito.

Nessa miragem no espelho, nessa devoluçăo da imagem, Raimundo acaba por nāo se constituir enquanto sujeito completo, uno, marcando assim não a identificação com Sardento, mas a diferença que é a sua marca. $E$ a parte que não consegue tampar o que falta no todo, pois esse todo tem uma falta que nunca será tamponada, o que vai fazer com que o sujeito desejante continue sempre buscando alguma coisa ou alguém para completar o que the falta.

Segundo VOLICH (1991, p. 40)

"as fantasias são construçōes psíquicas que tecem a realidade. $A$ realidade psíquica, impregnada com fantasias, a maneira corpórea de tratar $\theta$ contomar o Real sem sucesso".

E ainda:

"... a tunção do princtioio do prazer é proputsionar o ser humano a buscar algo que deverá ser encontrado, mas que ele nunca será capaz de atingir. Nesse ponto está o essencial, a relaçấo do que se chama a lei da interdiçấ, a lei do incesto". (p. 41)

A presença de Sardento enquanto o duplo de Raimundo nāo representa o fim de seu conflito, pois a imagem devolvida mantém a presença da falta. E a busca continua.

É em Caralâmpia que Raimundo vai buscar novamente se completar. Essa personagem representa como Sardento a contradiçăo interior de Raimundo e a sua necessidade de resolvê-la, mas a configuração feminina de Caralâmpia já traz a marca de um duplo marcado pela diferença.

Enquanto Caralâmpia é amada por todas as crian- 
ças do pals de Tatipirun, Raimundo nāo tem o afeto dos meninos de Cambaracá, nome dado por ele ao mundo real onde vive. Caralâmpia vira e desvira princesa a qualquer hora; Raimundo rejeita a mudança de seu nome para Pirundo ou Nundéu como propōe Talima, outra personagem do mundo imaginário. Enquanto Raimı ndo aceita apenas vestir-se com uma túnica que todas as crianças usam, Caralámpia apresenta-se como fantasia total, vestindo uma "túnica azulada cor das nuvens do céu, coroada de rosas, um broche de vaga-lume no peito, e pulseira de cobras de coral". (RAMOS, 1984, p. 44)

O fato de Caralâmpia enfeitar-se com cobras nos braços causa em Raimundo muito medo e indignaçāo, e ele pede a ela que tire essa "bicharia" de cima do corpo, pois que as cobras mordem.

Mas as cobras do mundo imaginário sāo seres talantes e dizem que Raimundo "é um selvagem, que na terra dele as coisas vivas mordem" (RAMOS, 1984, p. 405). Essa enunciaçāo pelas cobras de sua natureza inofensivel parece romper a distância que separa Raimundo de Caralampia, ou seja, de seu duplo sexual.

As cobras, enquanto símbolo fálico, parecem mostrar a dificuldade de Raimundo de se defrontar com a diferença sexual, de se assumir enquanto sujeito marcado pela masculinidade.

Esse aspecto simbólico remete a outra questäo que é a personagem de Caralâmpia só aparecer no final da história. O fato de Caralámpia permanecer desaparecida por muito tempo na história, enquanto Raimundo passeia pelo pais imaginário, questionando as diferenças existentes entre o seu mundo real e as terras de Tatipirun, denota, como no caso de Sardento, a recusa de Raimundo de se ver através de seu duplo.

O não aparecimento de Caralâmpia adquire um significado muito importante se se aceitar a idéia de que ela encontra-se desaparecida através da criação do imaginário de Raimundo, que ainda nāo pode se defrontar com a diferença de sexo, deslocada para a diferença de aparência que Caralâmpia apresenta.

Alếm disso, Caralâmpia representa na fantasia de Raimundo a transgressão da semelhança física das crianças do mundo imaginário que Raimundo havia criado. Diz ela:

\footnotetext{
" Andei numa terra diferente das outras, uma terra onde as arvores crescem com as fothas para baixo e as ralzes para cima As aranhas săo do tamanho da gente, e as pessozs do tamanho de aranhas. (...) Os guris que eu vi tem duas caboças, cada uma com quatro olhos, dois na frente e dois atrás" (RAMCS, 1984, p. 54).
}

Caralâmpia, no delírio de Raimundo, se apresenta então como a abstração de uma abstração, criando um outro mundo imaginário, passando num processo interminável da semelhança para a diferença.

Tanto no caso de Sardento como no de Caralâmpia, - que há a continuidade do mesmo processo de busca de Raimundo. O retardamento da fala de Sardento como a demora no aparecimento de Caralámpia simbolizam assim a dificuldade de Raimundo se ver, de se encontrar, de se identificar como sujeito sexualizado.

\subsubsection{Entre avanços e recuos}

Logo no inlcio da história Raimundo cede ao pedido do Tronco para que ele vista a túnica presenteada pelas aranhas, que todas as crianças de Tatipirun usam. $O$ menino aceita, e ao despir-se de suas roupas, que as aranhas consideram "arreios", e vestir-se com uma túnica azul igual às das crianças, ele passa a compartilhar da realidade de vida do mundo imaginário, e tornar-se um igual.

Em outras situações Raimundo rejeita a mudança de seu nome para Pirundo e Mundéu, sugerida por Talima, menina bonita, "meio desparafusada, mas com um coraçãozinho de açúcar" (RAMOS, 1984, p. 28). As crianças, que num primeiro momento vêem Raimundo como um visitante vindo de outras terras, no decorrer da hist $\delta$ ria insistem para que ele fique morando em Tatipirun. $E$ assim propōem para Raimundo um nome novo, insistindo Talima em the chamar Pirundo.

Uma análise mais detalhada dos nomes Pirundo e Mundêu atribuldos a Raimundo parece revelar um significado que uma simples leitura descompromissada não consegue captar. Esses três nomes guardam entre si sons e sllabas de Tatipirun, o que evidencia uma relação de reciprocidade entre eles. Graficamente tem-se:

$$
\begin{aligned}
& \text { TatiPIRUN } \\
& \text { PIRUNDO } \\
& \text { RaIMUNDO } \\
& \text { MUNDéU }
\end{aligned}
$$

A intersecção de letras comuns aos nomes parece indicar uma intermediação do mundo real e do mundo imaginário. Enquanto Tatipirun, Pirundo e Mundéu fazem parte do mundo imaginário, Raimundo representa o mundo real.

PIRUNDO é a junção de PIRUIN de Tatipirun e DO de Raimundo, o que evidencia a confluência do real e do imaginário.

Em nlvel semántico, Mundêu siginifica, "armadilha de caça", ou ainda no sentido figurativo, "qualquer caso ou coisa, que ameaça cair, constituindo perigo" (FERREIRA, p. 960), o que evidencia a ultrapassagem do limite.

Ao não aceitar trocar seu nome para Pirundo, Raimundo parece rejeitar a sua integraçāo mais compromissada com o mundo fantástico de Tatipirun; mas ao rejeitar mais veementemente chamar-se Mundéu, Raimundo mostra năo estar em perigo, com ameaça de desmoronar psicologicamente. $O$ anagrama MUNDO, contido no nome RaiMUNDO, se constitui no seu lugar no mundo que só se constrói através da simbolização pela viagem delirante de Raimundo no MUNDO de Tatipirun. 
Ao não mudar seu nome, Raimundo nāo muda sua identidade, não se alienando no mundo imaginário, e ao assumir o seu próprio nome, Raimundo parece aceitar também a sua própria falta.

Na sabedoria popular nordestina, Raimundo e todo aquele que teve dificuldade de nascer, recebendo esse nome em homenagem ao Santo Raimundo que ê invocado quando o nascimento de uma criança se torna diflcil.

Esse vir ao mundo, que é o nascimento difícil, também pode ser estendido ao vir ao mundo enquanto ser, sujeito de si próprio. $E$ isso parece ser a razão de Raimundo buscar no dellíio, através do jogo dos opostos, a forma de se encontrar.

O título do livro antecipa assim a razāo de ser da história, denotando pelo adjetivo "pelados" a marca da personagem Raimundo. Enquanto a expressão "meninos pelados", no sentido denotativo, significa meninos sem roupas, simbolicamente denuncia a falta, a ausência de alguma coisa que Raimundo busca cobrir.

Logo no início da história o narrador mostra que Raimundo aceita a falta em razão dos meninos do mundo real o chamarem " $O$ pelado!" sempre que o vêem. Isso faz com que ele passe a "se assinar a carvāo, nas paredes: Dr. Raimundo Pelado" (RAMOS, 1984, p. 7).

Nesse sentido compreende-se melhor porque Raimundo aceita vestir-se como as crianças do mundo imaginário de Tatipirun, mas rejeita ser chamado de Pirundo ou Mundéu. Enquanto a troca de roupa representa apenas a mudança do aspecto exterior, social; a troca de nome implica na renúncia daquilo que se constitui o seu ser, o seu sê-lo, o seu selo, a sua marca original. $E$ isso Raimundo năo quer, pois já se reconheceu como pelado, como castrado.

Há nessa recusa, a meu ver, uma tomada de posição fundamental de renúncia à mudança de identidade, $e$ a permanência do nome de origem parece ser importante enquanto nāo abandono de sua posição como sujeito.

Embora em dellrio, Raimundo não abandona, como em um surto psicótico de alucinaçāo, o vínculo com o mundo real, o que representa a grande força propulsora da vida, que se constrói pela busca incessante da realizaçăo do desejo.

\section{A Geografia e o Lugar do Sujeito no Mundo}

Raimundo continua a ser um "viajante", como denomina o narrador, que está de passagem pelas terras fantasiosas de Tatipirun, mas que em momento algum decide fixar-se nesse lugar, pois a sua consciência a todo momento the chama de volta para o seu mundo real. $A$ lembrança em toda a história de que precisa estudar a liçảo de geografia parece ser o vínculo que enraiza Raimundo ao mundo real, como se pode perceber pelos exemplos abaixo:

- Este lugar ótimo, suspirou Raimundo, mas acho que preciso voltar. Preciso estudar a minha liço de geografia". (RAMOS, 1984, p. 24)
“- Preciso voltar e estudar minha liçáo de geografia, suspirou Raimundo". (p. 54)

(p. 55)

"- Preciso vohtar, murmurou Raimundo".

"- Năo posso, gemeu Raimundo. Eu queria ficar com vocés, mas preciso estudar a minha liçao de geografia". (p. 57)

“- (...) Mas tenho obrigaçठes, entende? Preciso estudar a minha liçăo de seografia. Adeus!" (p. 58)

Err nivel semântico, Geografia remete a topografia, a lugar enquanto espaço físico, o que significa que Raimundo desejava voltar para o seu mundo real; em nivel simtólico, geografia parece remeter à localização do sujeito em seu mundo interior. A recorrência ao estudo da liçāo de geografia enfatiza a necessiciade de Raimundo se situar, de ocupar um espaço como sujeito de seu próprio ser. A geografia seria então o lugar de constituição do EU, de que fala Lacan, ao mostrar que a criação do mundo imaginário representa a busca de realizaçăo do desejo. Todavia, como o desejo é falta, é insatisfação, ele nunca poderá ser satisfeito, passando assim em forma de demanda para a cadeia significante e, através do deslocamento metonImico das situaçōes vividas, prosseguir na continuidade da busca.

É nesse sentido que a história acaba por nāo oferecer uma resolução para o problema de Raimundo. A sua busca no mundo imaginário permite somente a possibilidade de ele se relacionar com c: seu duplo, com o outro. O sujeito desejante necessita conviver com a falta para que, consciente disso, possa reconhecer um limite.

No final da história, a volta da personagem para o mundo real sinaliza para o fim do delírio, mas nåo do conflito, pois o fluxo de consciência de Raimundo não deixa pistas seguras de que ele não voltará ao mundo imaginário de Tatipirun.

\section{A LITERATURA E A VIDA}

Atribuir significaçāo à obra infanto-juvenil de Graciliano Ramos, A terra dos meninos pelados, dando-Ihe um (possivel) sentido, foi o propósito deste trabalho. Se na introduçāo enunciei a questionabilidade de minha análise, agora, após ter passadc pelo processo sofrido da necessidade de oferecer uma leitura que encontrasse sustentaçāo no texto, concluo dizendo que a obra em questão ê, em ưltima instância, a busca do ser humano de seu crescimento interior, de sua identidade enquanto ser no mundo dos humanos.

Essa constatação evidencia que a constituiçăo do ser humano se pauta pela complexidade psicológica, apresentando-se pela integraçăo do mundo consciente e inconsciente, através da simbolização de seus desejos.

E como "o incorsciente é um saber que não se sabe 
enquanto saber", ele (o inconscientel acaba por se mostrar através de símbolos que se estruturam em linguagem, necessitando de interpretação.

Como toda obra literária se constı́ói pela linguagem estética, o caminho da análise foi dar sentido a um todo organizado estrutural e simbolicamente, destacando o modo de formar do enunciado reirativo, e o processo de enunciaçăo como responsáveis pela significação dz ris- tória. A beleza dessa narrativa está, portanto, nåo só na viagem fantóstica do protagonista, mas também na significaçäo simbólica dessa viagem e na sua genesis estético-estrutural.

A análise de A terre dos meninos pelados, através das teorias psicanalficas de Freud e Lacan, acabou por mostrar que a literatura ficcionaliza a vida humana, transpondo-a do "real para o ilusório por meio de uma estilização formal". (CANDIDO, 1973, p. 53)

CARVALHO, N.C. de. The endless trip through the lands of the naked boys: a psychoanalytical analysis. Semina: Ci. Soc/Hum., Londrina, v. 13, n. 3, p. 180-185, Sept. 1992.

ABSTRACT: The present article is a study about the book written by Graciliano Ramos, named $A$ terra dos meninos pelados. The authour ha tried to show, through the Psychoanalysis of S. Freud and J. Lacan how the narrative structure reveals delirium as a mechanism used by character to fulfill his wishes.

KEY-WORDS: Literature; Psychoanalysis; Narrative Structure; Real Word/immaginary word; Symbols; Delirium.

\section{REFERÊNCIAS BIBLIOGRAFICAS}

CABAS, Antonio Godino. Curso e discurso na obra de Jecques Lacan. Rio de Jane iro: Edltora Moraes, [198], p. 16-59. Colaço da Blblotoca Freudiana Brasilelra.

CANDIDO, Amtonio. Uteratura e sccledade. 3. ed, Sáo Paulo: Necional, 1973. p. 53-58.

CHALHUB, Samira. (m) pasees: theratura e psicandise. In CONGRESSO BRASILEIRO DE SEMIÓTICA, 2, SAo Paulo, 1988. Anais. Suo Paulo: EDUC, 1988. p. 171-179.
GARClA ROZA, Lulz Alfredo. Froud o inconsciente. 4.ed. Rlo de Janelro: Zahar, [19_], p. 61-92; 139-150.

RAMOS, Gracllano. A terra dos meninos pelados Hustracto de Flortano Tebxelra. 7. ed. Flo de Janelro: Record, 1984.

VOLKH, Renata. A pulato froudlana: sua insinuaço com o real. PERCURSOS: Revista de palcanáltee, Rlo de Janeiro, v. 3, n. 5/6, p. 39-43, sat. 1991 .

Recebido para publicaçào em 16/03/92 